\title{
Surgical results for hypertrophic obstructive cardiomyopathy: More than an institutional niche
}

Dawn S. Hui, MD, and Richard Lee, MD, MBA

From the Saint Louis University, St Louis, Mo.

Disclosures: Authors have nothing to disclose with regard to commercial support.

Received for publication Sept 20, 2018; accepted for publication Sept 21, 2018; available ahead of print Oct 29, 2018 .

Address for reprints: Richard Lee, MD, MBA, 48 Picardy Lane, St Louis, MO 63124 (E-mail: rick.lee@ health. slu.edu).

J Thorac Cardiovasc Surg 2019;157:316-7

$0022-5223 / \$ 36.00$

Copyright (c) 2018 by The American Association for Thoracic Surgery

https://doi.org/10.1016/j.jtcvs.2018.09.061

In this edition of the Journal, Nguyen and colleagues ${ }^{1}$ report on their institutional comparative experience of surgical myectomy (SM) and alcohol septal ablation for hypertrophic obstructive cardiomyopathy (HOCM). Their propensity score-matched comparison found that SM offered similar survival, superior gradient relief, and a lower reintervention rate. Surgical results in the propensity scorematched cohort were excellent, with $0 \%$ in-hospital mortality, $3.9 \%$ permanent pacemaker insertion, minimal resting gradients at all time points after surgery, and only 1 reintervention. These data continue to support the American College of Cardiology/European Society of Cardiology recommendation for $\mathrm{SM}$ as the gold standard treatment for patients with HOCM meeting indications for an intervention. ${ }^{2}$

In the study, Nguyen and colleagues ${ }^{1}$ reported that over 18 years, 2407 isolated SMs were performed at the Mayo Clinic. This translates to an average of at least 133 SMs annually (considering the fact that concomitant SMs were excluded). The magnitude of these numbers should be considered in applying the study results. The guidelines for SM recommend that the operation be performed in centers with an annual volume of at least 20 . In the mitral realm, Bolling and colleagues ${ }^{3}$ first reported that the median number of mitral valve operations per surgeon per year was 5 , and high volume independently predicted repair. Chikwe and colleagues ${ }^{4}$ subsequently showed a median annual mitral repair volume of 10 per surgeon in New York State, finding that repair rates were associated with annual volume and that durability and survival were additional benefits with a threshold of 25 cases per year. ${ }^{4}$

What is the disparity between the Mayo Clinic and the national practice for SM? This is an important question as we face the need for surgeon allocation. In a study of the US Nationwide Inpatient Database (a 20\% stratified sample of all nonfederal US hospitals), the median number of SM cases per institution per year was 1.0. Sixty percent of institutions performed 10 or less SMs per year, and only 4

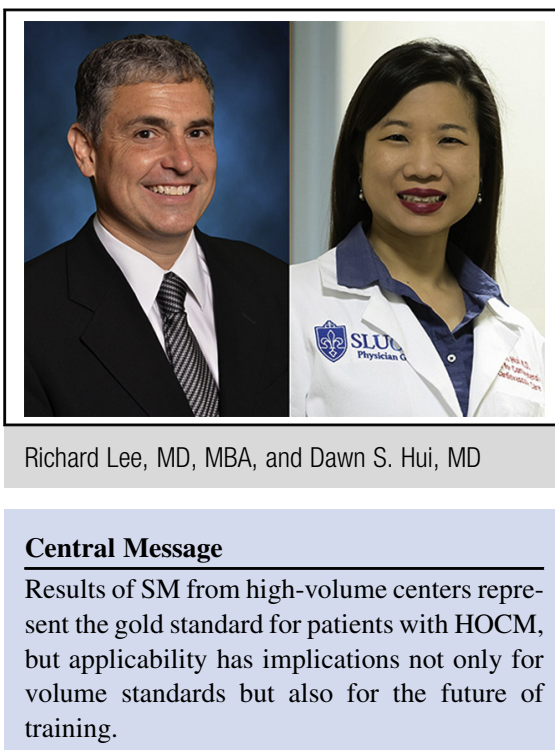

See Article page 306. institutions performed a full $36 \%$ of all SMs. ${ }^{5}$ The lowest tertile of SM volume was an independent predictor of inhospital all-cause mortality (adjusted odds ratio, 3.11 ) and bleeding (odds ratio, 3.77). In contrast, adverse events were not significantly higher in the lowest tertile of alcohol septal ablation.

Extrapolation of the figures from the US Nationwide Inpatient Database suggests that nationally, there are several thousand SMs per year. However, the finding that many institutions are low volume for SM means that it is difficult to also extrapolate Nguyen and colleagues' findings ${ }^{1}$ to all patients who are eligible for HCM treatment. The dilemma raised is that although data support performing SM at high-volume centers, the small number of such centers limits the dissemination of experience with this highly specialized operation. That outcomes for alcohol septal ablation do not vary by center volume may risk furthering the "accelerated enthusiasm for ablation," which was raised as a concern by the American College of Cardiology/European Society of Cardiology writing committee. The committee noted the recent high volume of septal ablation relative to SM, that SM frequency was decreasing, and that the relative short-term periprocedural ease of ablation was a potential temptation to relax the criteria for intervention. Center volume aside, septal ablation is not in every circumstance an equivalent alternative to SM. We know 
that septal ablation is of uncertain effectiveness when septal thickness is greater than $30 \mathrm{~mm} .{ }^{6}$ Creation of a substrate for lethal re-entrant arrhythmias as a consequence of alcohol ablation also has been cited, although this is a theoretical concern that needs further data. ${ }^{1}$

On the other hand, it is our duty to establish benchmark data including gradient reduction and permanent pacemaker rate, and the duty of any center willing to perform them to live up to that standard. In an environment where patient-reported outcomes are increasingly important, variables including quality of life and return to work also should be examined. To protect against the slippery slope of alcohol septal ablation as first-line therapy, adequate SM surgeons must be trained and available as part of a comprehensive HOCM program. How can this be achieved? The concept of "supersubspecialization" has recently been introduced by the Society of Thoracic Surgeons. ${ }^{7}$ Those who are experts in SM have proposed mentorship, including possible formal fellowships. ${ }^{8}$ These moves will not only preserve but also disseminate the surgical expertise and wisdom to future surgeons such that the best option remains viable for patients.

\section{References}

1. Nguyen A, Schaff HV, Hang D, Nishimura RA, Geske JB, Dearani JA, et al. Surgical myectomy versus alcohol septal ablation for obstructive hypertrophic cardiomyopathy: a propensity score-matched cohort. J Thorac Cardiovasc Surg. 2019; 157:306-15.e3.

2. Maron BJ, McKenna WJ, Danielson GK, Kappenberger LJ, Kuhn HJ, Seidman CE, et al. Task force on clinical expert consensus documents. American College of Cardiology; committee for practice guidelines. European Society of Cardiology. American College of Cardiology/European Society of Cardiology clinical expert consensus document on hypertrophic cardiomyopathy Guidelines. J Am Coll Cardiol. 2003;42:1687-713.

3. Bolling SF, Li S, O’Brien SM, Brennan M, Prager RL, Gammie JS. Predictors of mitral valve repair: clinical and surgeon factors. Ann Thorac Surg. 2010;90:1904-11.

4. Chikwe J, Toyoda N, Anyanwu AC, Itagaki S, Egorova NN, Boateng P, et al. Relation of mitral valve surgery volume to repair rate, durability, and survival. J Am Coll Cardiol. 2017;29:2397-406.

5. Kim LK, Swaminatah RV, Looser P, Minutello RM, Wong SC, Bergman G, et al. Hospital volume outcomes after septal myectomy and alcohol septal ablation for treatment of obstructive hypertrophic cardiomyopathy. JAMA Cardiol. 2016;1:324-32.

6. Gersh BJ, Maron BJ, Bonow RO, Dearani JA, Fifer MA, Link MS, et al. 2011 ACCF/AHA guideline for the diagnosis and treatment of hypertrophic cardiomyopathy: executive summary a report of the American College of Cardiology Foundation/American Heart Association task force on practice guidelines. J Thorac Cardiovasc Surg. 2011;142:1303-38.

7. The Society of Thoracic Surgeons. Is 'supersubspecialization' the future of cardiothoracic surgery training? STS News. Summer 2018;23:1.

8. Maron BJ, Dearani JA, Maron MS, Ommen SR, Rastegar H, Nishimura RA, et al Why we need more septal myectomy surgeons: an emerging recognition. $J$ Thorac Cardiovasc Surg. 2017;154:1681-5. 